\title{
Small hive beetle diagnosis and control in naturally infested honeybee colonies using bottom board traps and CheckMite + strips
}

\author{
Peter Neumann • Dorothee Hoffmann
}

Received: 14 May 2007 / Revised: 19 September 2007 / Accepted: 24 September 2007 / Published online: 9 October 2007

(C) Springer-Verlag 2007

\begin{abstract}
The efficacy of bottom board traps and CheckMite + strips using Coumaphos, for small hive beetle (SHB) diagnosis and control was studied in Australia. Colonies in three apiaries $(N=10$ each) were surveyed for SHB. In two apiaries, colonies received bottom board traps (cardboard or plastic) with CheckMite + strips and in the control apiary, traps without strips. After 5 days, all colonies were surveyed again, killed and dissected to quantify non-detected SHB. Significant differences in the number of live SHB were found between apiaries after treatment, supporting the fact that Coumaphos traps are efficient (trap mortality: $94.73 \pm 0.06 \%$ cardboard and $99.53 \pm 0.01 \%$ plastic). However, mortality assessment at the colony level $(53.29 \pm 31.30 \%)$, showed that only a limited SHB proportion was affected. Post mortem colony inspections revealed that $14.06 \pm 10.53 \%$ SHB were undetected, which should be considered for quantitative diagnosis. Bottom board traps provided a first estimate of infestation levels $(43.03 \pm 27.02 \%)$.
\end{abstract}

P. Neumann $(\bowtie)$

Swiss Bee Research Centre,

Agroscope Liebefeld-Posieux Research Station ALP,

3003 Bern, Switzerland

e-mail: peter.neumann@alp.admin.ch

P. Neumann

Department of Zoology and Entomology,

Rhodes University, 6140 Grahamstown, South Africa

\section{P. Neumann}

Eastern Bee Research Institute of Yunnan Agricultural University, Heilongtan, Kunming, Yunnan Province, China

D. Hoffmann

Institut für Biologie, Martin-Luther-Universität,

Halle-Wittenberg, 06099 Halle (Saale), Germany
Keywords Aethina tumida $\cdot$ Apis mellifera $\cdot$ Coumaphos · Honeybee $\cdot$ Pest control $\cdot$ Small hive beetle

\section{Introduction}

The small hive beetle (SHB), Aethina tumida Murray (Coleoptera: Nitidulidae), is a parasite and scavenger of honeybee colonies, Apis mellifera L. native from sub-Saharan Africa (Lundie 1940; Schmolke 1974; cf. Hepburn and Radloff 1998). In its native range, it is usually considered only a minor pest (Lundie 1940; Hepburn and Radloff 1998; but see Mutsaers 1991, 2006). The SHB has recently become an invasive species in North America (1996), Egypt (2000) and Australia (2002; Elzen et al. 1999; cf. Neumann and Elzen 2004). In North America (cf. Hood 2004; cf. Neumann and Elzen 2004), it can cause considerable damage to European-derived honeybee colonies. Colonies are infested by flying adult SHB (Elzen et al. 1999). Inside colonies, adult SHB feed on brood, pollen and honey (Lundie 1940; Ellis et al. 2002a). They are also fed by the workers (Ellis et al. 2002b), and mate and oviposit in the colony (Neumann and Elzen 2004). The emerging SHB larvae develop until the wandering stage and then leave the nest for pupation in the soil (Lundie 1940). While the adults have comparatively little impact on the colony (Ellis et al. 2003a), the larvae can cause severe damage to combs (Lundie 1940; Schmolke 1974), often resulting in the full structural collapse of the nest (Neumann and Elzen 2004). Newly eclosed adults invade host colonies, thereby completing the life cycle of A. tumida (Neumann and Elzen 2004).

A. tumida can be successfully treated in beehives with CheckMite + strips $^{\mathrm{TM}}$ (Elzen et al. 1999), containing Coumaphos, which is also used to control the parasitic mite 
Varroa destructor Anderson and Trueman. Elzen et al. (1999) attached CheckMite + strips $^{\mathrm{TM}}(10 \%$ w/w Coumaphos) to bottom board trapping devices made of corrugated cardboard. They reported a high efficacy with up to $90.2 \%$ mortality of adult SHB. However, Elzen et al. (1999) evaluated the number of SHB only on the bottom boards of colonies. Since SHB are also found in other areas of the hive [e.g. on the combs, underneath the top lid or in small cracks in the hive walls (Lundie 1940; Schmolke 1974; Neumann and Elzen 2004)], a quantification of SHB restricted to the bottom boards underestimates the overall infestation levels. Thus, in order to evaluate the efficacy of CheckMite + strips $^{\mathrm{TM}}$ against natural infestations of $A$. tumida in honeybee colonies, it appears crucial to inspect whole colonies for the presence of SHB, both before and after treatment. Moreover, adult SHB are active flyers (Elzen et al. 1999) and are known to frequently migrate between colonies of the same apiary (Ellis et al. 2003a), regardless of colony strength (Lundie 1940). Unless a chemical treatment causes immediate SHB mortality, this high mobility of SHB may interfere with an efficacy assay, if test and control colonies are at the same apiary (as in the study of Elzen et al. 1999). Thus, it seems crucial for an efficacy test to evaluate SHB population sizes in infested colonies at separated test and control apiaries. For such evaluations of infested colonies, visual inspections are necessary, which, however, suffer from a number of the following potential shortcomings.

During inspections of infested colonies, adult SHB often hide on the bottom of cells, in the debris, or in small cracks (Lundie 1940; Schmolke 1974; Neumann et al. 2001; Neumann and Elzen 2004). Furthermore, both African and European bees encapsulate adult SHB in propolis prisons (Neumann et al. 2001; Ellis et al. 2003b, c, 2004). Thus, adult SHB are often difficult to spot, especially in case of dark old combs. SHB larvae may also hide in the debris (Spiewok and Neumann 2006). Finally, adult SHB may simply fly away during inspections and may return when the colonies have settled. Therefore, it is likely that even careful visual surveys of colonies for the presence of SHB adults and larvae may considerably underestimate the actual infestation levels due to their behaviour and/or colouration, imposing difficulties for an accurate quantitative diagnosis of this pest. Trapping devices (e.g. Elzen et al. 1999) may facilitate a quantitative diagnosis but the proportion of SHB within and outside such traps must be known. A first approach towards a quantitative diagnosis of SHB would be to lock up infested hives after inspections, then kill and dissect the colonies to estimate the number of nondetected SHB. However, to our knowledge such data are not yet available.
In our study we had two objectives:

1. We evaluated the efficacy of Coumaphos (in the application form of CheckMite + strips in bottom board trapping devices) for the control of SHB in naturally infested colonies. The study was conducted in Australia using a visual whole colony approach in three apiaries.

2. Aiming towards quantitative diagnosis of SHB, we also assessed the proportion of non-detected SHB during visual inspections.

\section{Materials and methods}

Experimental colonies and test apiaries

Unrelated queenright colonies $(N=30)$ of mixed European origin (predominantly $A$. $m$. ligustica), which had each brood of all stages and a similar strength, were placed in 10-frame standard Langstroth hives with two boxes. The colonies were arranged in three apiaries (A, B and $\mathrm{C}$ with $N=10$ hives each) in bush land in the Hawkesbury area, NSW, Australia. The apiaries were separated by at least $3 \mathrm{~km}$ from each other and by more than $15 \mathrm{~km}$ from any other apiaries. Two apiaries (A, B) were used for testing the CheckMite + strips and the third one $(C)$ served as a control. After transport, the colonies were given at least 4 days to settle before they were used in the experiments. The experiments were conducted in November 2005, which is local springtime.

Visual surveys of colonies for small hive beetles

Before treatment, all colonies were carefully surveyed in a standardized fashion for the presence of dead and live SHB adults and larvae as follows: (1) removal and first inspection of the top lid; (2) an empty box was placed on the top lid; (3) starting from the outer frames, the frames were removed one by one from the top box, screened in a grid fashion and then placed in the empty box; (4) step 3 was repeated for the bottom box of the colony using the then empty top box and another lid; (5) the hive walls and the bottom board, including propolis and debris, were carefully examined; (6) all frames were reintroduced in the same order in the original boxes; (7) second survey of the top lid (because SHB may have not been detected during the first survey and may hide between the lid and the frames, away from the daylight), survey of the other lid and of the then empty boxes after the respective frame removals; (8) all hive boxes were placed in their original positions. During these surveys, colony sizes were evaluated using the stan- 
dard Liebefeld method (Imdorf et al. 1987). All live SHB were individually collected from the colonies using especially designed aspirators. All collected SHB were stored in separate plastic containers for each colony $(10 \times 5 \times 10 \mathrm{~cm}$ with round, mesh-covered holes on top), provided with sugar water-soaked cotton wool, and transported to the laboratory for quantification. Surveys were only performed in the morning and late afternoon to prevent heat stress of both bees and SHB.

Efficacy testing of two trapping devices

Trapping devices using $(15 \times 15 \mathrm{~cm})$ pieces of corrugated cardboard were installed in the hives of apiary A according to Elzen et al. (1999). One surface was stripped off to expose the corrugations, then two CheckMite + strips (Bayer Corp.) were stapled onto the exposed corrugated side. We also stapled a thin piece of wood $(15 \times 15 \times 0.5 \mathrm{~cm})$ on top of the cardboard to prevent the bees from chewing it. In each hive the device was placed in the middle of the bottom board with the treatment side facing down.

Trapping devices using corrugated plastic sheets $(15 \times 15 \times 1.5 \mathrm{~cm}$, with a gauge of $0.5 \mathrm{~cm})$ were installed in the colonies of apiary B in exactly the same way as in group A. All CheckMite + strips were placed parallel to corrugations similar to the study of Elzen et al. (1999).

The control colonies of apiary $\mathrm{C}$ received trapping devices without the Coumaphos treatment $(N=5$ colonies each for both types of trapping devices). After installation of the trapping devices, all adult SHB collected were reintroduced into their respective host colonies on the frames of the top box. Five days after installation of the trapping devices, all colonies and trapping devices were again carefully examined in the way described in paragraph "Visual surveys of colonies for small hive beetles". All SHB adults and larvae were collected in the hive and under the trapping devices and transferred to the laboratory for quantification and to ascertain whether they were dead or alive.

Estimate of non-detected small hive beetles during visual surveys

After the inspections, all colonies were allowed to settle. Then, the hives were completely sealed with masking tape. The colonies were killed by quickly opening the top lid and pouring $500 \mathrm{ml}$ of standard petrol fuel (Australian Fuel Quality Standards Act 2000) into the top box. These colonies were then transported to the laboratory and stored in a cool room. Within the following 5 days, all hives were completely and thoroughly dissected (including splintering of the side walls and bottom boards, uncapping of sealed brood and honey, survey of debris and piles of dead bees, etc.) to assess the number of adult and larval SHB.
Data analysis

ANOVAs and Newman-Keuls post hoc comparisons were performed to test for differences:

- In the number of live adult SHB between and within apiaries, before and after treatment

- In the number of bees per colony between apiaries

- In the proportions of non-detected adult SHB during visual inspections. Percentages were arcsine transformed.

Paired samples $t$ tests were conducted for each apiary to test for differences in the number of live adult SHB, before and after treatment. Percentages of mortality were corrected with control mortaliy using Abbot's formula.

Simple correlations were calculated between:

- Number of all adult SHB found during the inspections and the post mortem dissections

- The proportion of SHB not detected during the inspections and the number of bees per colony

- The number of bees and the number of live SHB before treatment

- The number of bees per control colony and the number of live SHB found underneath the trapping devices.

The program Statistica ${ }^{\odot}$ was used for the statistical analyses. Means are provided with the standard deviation, SD.

\section{Results}

Visual survey of colonies for small hive beetles

Prior to the treatment, one colony in apiary A was destroyed by SHB. The bees had absconded and several thousand SHB larvae as well as the typical signs of damage were found. A total of 9,744 adult SHBs were counted in this study, 7,346 of which were alive.

During the first inspections before treatment, no significant differences in the number of bees per colony were found between apiaries (apiary A: 20,694 $\pm 6,977$; apiary B: $19,215 \pm 8,258$; apiary C: $20,165 \pm 6,897$; ANOVA: $d f=2, \quad F=0.098, \quad P=0.907)$. Likewise, no significant differences in the numbers of live adult SHB were found between apiaries before treatment (Fig. 1; ANOVA: $d f=2$, $F=3.351, P>0.5)$. Finally, the number of bees in each colony did not correlate with the number of live SHB before treatment $\left(r^{2}=-0.127, P=0.513\right)$.

After treatment, significant differences in the numbers of live adult SHB were found between apiaries (ANOVA: $d f=2, F=10.58, P<0.0001)$. While there were no significant differences between apiaries A and B (Newman-Keuls test: $P>0.53$ ), both treatment apiaries differed significantly 


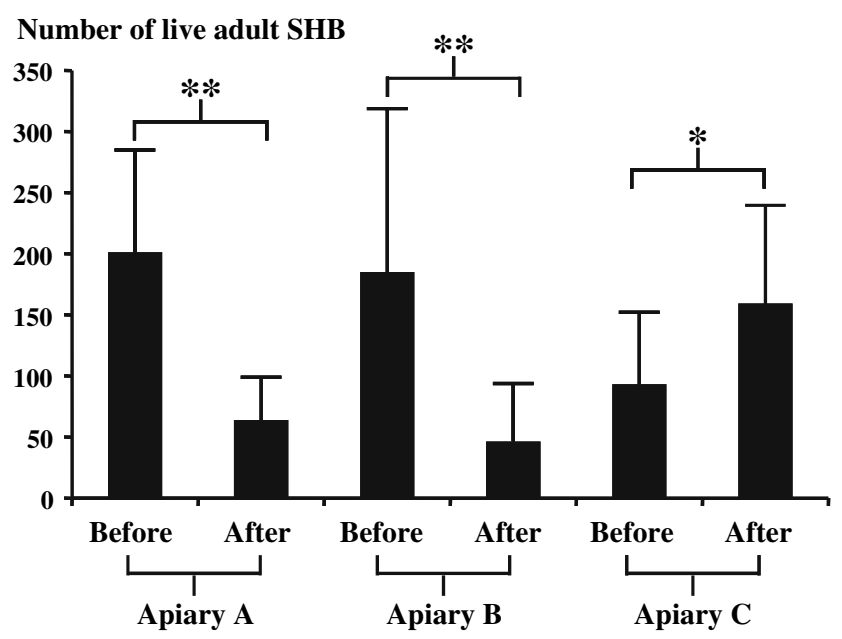

Fig. 1 Number of live adult SHB per infested colony $(N=29)$ detected during visual inspections at the two test apiaries $(A, B)$ and the control apiary $(C)$ before and after treatment. Vertical bars are standard deviations. Asterisks indicate significant differences (Mann-Whitney $U$ tests: $* P<0.05$; ** $P<0.01)$. Apiary $A$ : bottom boards with cardboard traps with Coumaphos. Apiary $B$ : bottom boards with plastic traps with Coumaphos. Apiary $C$ : bottom boards with cardboard and plastic traps without Coumaphos

from the control apiary in the number of live adult SHB (Newman-Keuls tests: A vs. C $P<0.002$; B vs. C $P<0.001)$. In apiaries $\mathrm{A}$ and $\mathrm{B}$, the numbers of live adult SHB were significantly smaller after treatment (Paired samples $t$ test; apiary A: $t=5.395, P<0.001$; apiary B: $t=2.898, P<0.02$ ), but significantly higher in the control apiary C (Mann-Whitney $U$ test; $t=-2.696, P<0.03$; Fig. 1).

The number of dead and live adult SHB in the remaining infested colonies $(N=29)$ inside and outside of bottom board traps detected during visual inspections at the two test apiaries (A, B) and the control apiary (C) after treatment is shown in Fig. 2. In the control colonies, $43 \pm 27 \%$ of the live adult SHB were found underneath the trapping devices. No significant differences were found between the two types of traps: in cardboard traps of apiary A there were $44 \pm 30$ live adult SHB and $43 \pm 27$ were found in plastic traps of apiary B (Mann-Whitney $U$ test; $Z=-0.104, P>0.90$ ).

During the survey after treatment, live SHB larvae were found exclusively in the debris on the bottom boards of three colonies (3, 5 and 3 larvae respectively) in the apiaries $\mathrm{A}$ and B. In one colony of apiary B, five dead larvae were found underneath the trapping device.

Efficacy tests of the two trapping devices

Underneath the trapping devices of control colonies, the mean percentage mortality of adult SHB was $29.73 \pm 33.11 \%$. The Abbot adjusted mortalities under-

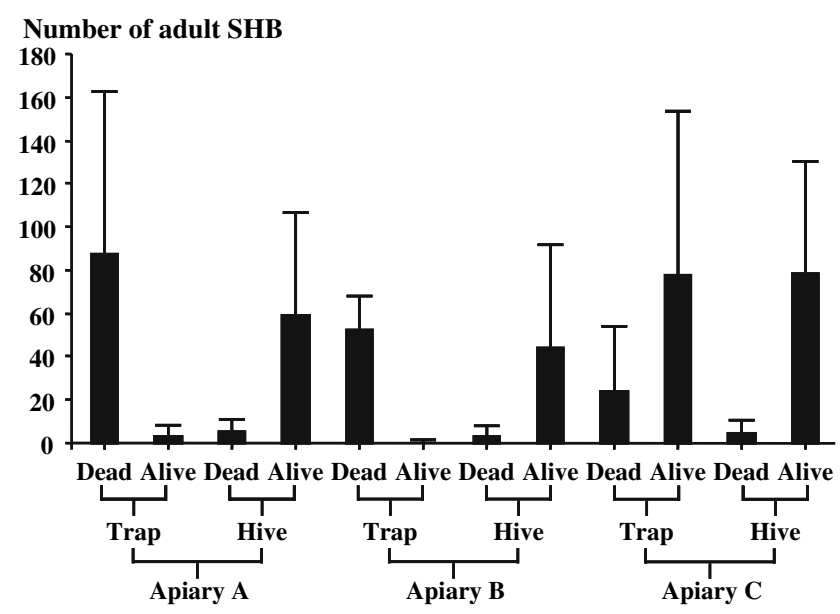

Fig. 2 Number of dead and live adult SHB per infested colony $(N=29)$ inside and outside of bottom board traps, detected during visual inspections at the two test apiaries $(A, B)$ and the control apiary $(C)$ after treatment. Vertical bars are standard deviations (Mann-Whitney $U$ tests: $P<0.05$ ). Apiary $A$ : bottom boards with cardboard traps with Coumaphos. Apiary $B$ : bottom boards with plastic traps with Coumaphos. Apiary $C$ : bottom boards with cardboard and plastic traps without Coumaphos

neath the trapping devices were $94.73 \pm 0.06 \%$ and $99.53 \pm 0.01 \%$ for apiary A and B, respectively, and significantly different from each other (Mann-Whitney $U$ test; $Z=-1.98, P<0.05)$.

For the whole colonies, the mean percentage mortality of adult SHB in the controls was $15.46 \pm 13.30 \%$. The Abbot adjusted mortalities were $47.42 \pm 33.37 \%$ and $58.57 \pm 30.07 \%$ for apiary A and B, respectively, and were not significantly different from each other (Mann-Whitney $U$ test; $Z=-0.1645, P>0.80$ ), resulting in an overall mortality of $53.29 \pm 31.30 \%$. The number of bees in the control colonies did not significantly correlate with the proportion of live SHB underneath the trapping devices $\left(r^{2}=-0.007, P=0.984\right)$.

Estimate of non-detected SHB during visual colony inspections

All bees in all dissected colonies were dead after the exposure to petrol. However, despite exposure to petrol for $\sim 12 \mathrm{~h}$, two SHB larvae and two adults were found alive in two colonies in small cracks in the bottom board burrowed underneath piles of dead bees. Taking all colonies together, $14.06 \pm 10.53 \%$ of the adult SHB remained undetected during visual inspections. No significant correlation was found between the number of all adult SHB found during the inspections and the post mortem counts of the remaining undetected individuals $\left(r^{2}=-0.1704, P>0.4\right)$. Likewise, the proportion of SHB not detected during the inspections did not correlate significantly with the number 
of bees per colony $\left(r^{2}=-0.069, P=0.722\right)$. In one colony, 173 SHB larvae at various developmental stages were found after uncapping a honey frame.

\section{Discussion}

Our data offer strong support to earlier studies (Elzen et al. 1999) that, considering the high mortality underneath the trapping devices with CheckMite + strips, Coumaphos can be efficient to control SHB. However, in our study, the mortality at the colony level was considerably lower than that reported by Elzen et al. (1999), probably because these authors restricted their study to the bottom boards. This suggests that the current application of Coumaphos should be adjusted to reach a higher proportion of SHB in the colony. Nevertheless, the treatment of all colonies with Coumaphos at infested apiaries significantly decreased the overall local SHB populations. In contrast, a considerable increase $(\sim 50 \%)$ in live SHB occurred within 5 days at the control apiary. This is most likely due to high SHB infestation levels of feral colonies in Australia. Indeed, at another apiary more than $15 \mathrm{~km}$ away from any other beehive ( $N=10$ colonies), an average of 40 new SHB infested each colony each day (data not shown).

We found no significant correlation between the number of bees per colony and the numbers of live SHB, supporting earlier findings that colony size is not relevant to SHB infestation levels (Neumann and Elzen 2004). While it seems implicit that Elzen et al. (1999) tested at least some colonies with successful larval reproduction on the combs, we had only a single colony with SHB larvae on the combs and five dead larvae in the trap which is too little information for concluding on the efficacy of the treatment against SHB larvae. Although the actual infestation levels were not given by Elzen et al. (1999), it may be assumed that the larvae numbers in their study were much higher than in ours, because when SHB reproduction occurs on the combs this usually results in the development of hundreds or thousands of larvae (Lundie 1940; cf. Neumann and Elzen 2004). Moreover, the trapped larvae in the study of Elzen et al. (1999) were older and closer to the wandering phase (Lundie 1940). Thus, they were more likely to enter the traps on the bottom boards (Elzen et al. 1999). The above points may explain the very low number of trapped larvae in our study.

In three colonies, we found a small number of SHB larvae ( 3,5 and 3 respectively) exclusively in the debris on the bottom board, confirming earlier reports of low level cryptic reproduction of SHB in honeybee colonies (Spiewok and Neumann 2006). Interestingly, we found 173 SHB larvae in different developmental stages during the post mortem dissections only underneath the capped honey of one colony. Since SHB do not reproduce on honeycombs alone (Ellis et al. 2002a), this suggests that the larvae have consumed foodstuff other than honey and that they were protected, because free-roaming larvae are readily removed from colonies by the bees (Neumann and Härtel 2004). The typical signs of damage by larvae (cf. Neumann and Elzen 2004) were lacking and the infestation with larvae, therefore, remained unnoticed during our study. Potential cryptic SHB reproduction underneath capped honey would mean further difficulties for SHB diagnosis.

It can be assumed that the tested product Coumaphos has not been applied on a large scale in Australia against SHB prior to our experiments. Unless the local SHB was introduced from the USA, we can therefore rule out that any resistance to Coumaphos has been developed as known from Varroa destructor (Spreafico et al. 2001; Pettis 2003). While Elzen et al. (1999) employed the trapping devices only for $48 \mathrm{~h}$ in the colonies, they remained for 5 days in our study. This longer period explains the number of dead adults in our control traps, which impeded cadaver removal by bees from underneath the traps. Furthermore, Elzen et al. (1999) restricted quantification to the bottom boards, where $42 \pm 32 \%$ of the adult SHB were found in the first surveys. Though traps may enhance SHB proportion on the bottom board, only $43 \pm 27 \%$ of the live adult SHB in our control colonies were found underneath the traps. Therefore, Elzen et al. (1999) possibly underestimated overall infestation levels and consequently overestimated treatment efficacy. This may explain the differences in the assessment of trap efficacy between Elzen et al. [(1999); $90.2 \pm 1.3 \%$ or $85.1 \pm 5.9 \%$ (means $\pm \mathrm{SE}$ )] and our study $[53.29 \pm 31.30 \%$ (means \pm SD)].

As expected from previous fieldwork (J.S. Pettis, personal communication), a high proportion of adult SHB remained undetected during the surveys (up to $40 \%$; $14.06 \pm 10.53 \%)$. High numbers of bees or high infestation levels by SHB, suspected to render beetle collection more difficult in colonies, do not reduce significantly the accuracy of beetle counts, because there was no correlation between the number of bees per colony and the proportion of undetected SHB assessed during post mortem dissection of hives. In addition, a higher number of bees appears unlikely to modify the number of SHB seeking refuge, because the number of bees in the control colonies did not correlate with the proportion of live SHB underneath the trapping devices. Despite the rather high variance observed $(43 \pm 27 \%)$, traps on the bottom boards appear to provide a practical first estimate of overall infestation levels with adult SHB. Although the efficacy of the bottom board treatments was rather low at the colony level, they significantly reduced the overall SHB population size at the test apiaries, Coumaphos can still be recommended in current application to control this pest. However, in order to increase the 
efficacy of Coumaphos traps, we suggest to prolong the exposure period to the local government approved maximum (e.g. 45 days in the US), and to recommend the use of more traps in infested colonies, e.g. on the side walls, between outer combs and on top of the frames. Furthermore, the efficacy of bottom board traps might be improved by using attractants, emptying the traps regularly and using more adequate materials. A significantly higher mortality was found underneath the plastic traps, possibly due to greater absorption of the Coumaphos into the plastic, thereby facilitating more effective contact with trapped SHB. Therefore, we recommend the use of plastic traps instead of cardboard, which also show a better sustainability under the moist conditions favouring SHB outbreaks in Africa (Mutsaers 1991), Florida (cf. Neumann and Elzen 2004) and Australia (M. Duncan, personal communication). As bees and bee products are not directly exposed to Coumaphos strips, they would be less contaminated by residues than after the regulatory application of two strips applied between combs for Varroa control.

Acknowledgments We are grateful to L. Brickhill-Goodwin, S. Spiewok, N. Ruppert, M. Duncan, F. Malfory, M. Louis, D. Rae and R. Spooner-Hart for their kind support. Two anonymous referees made constructive comments on the manuscript. The UWS provided laboratory facilities and Bayer Healthcare AG the Check-Mite + strips. Appreciation is also addressed to J. S. Pettis, M. Duncan and T. Imdorf for stimulating discussions and to H. R. Hepburn, J. Heine and P. Gallmann for comments on earlier drafts of the manuscript. Financial support was granted by Bayer Healthcare AG and an international visiting fellowship of UWS (PN).

\section{References}

Ellis JD, Neumann P, Hepburn HR, Elzen PJ (2002a) Longevity and reproductive success of Aethina tumida (Coleoptera: Nitidulidae) fed different natural diets. J Econ Entomol 95:902-907

Ellis JD, Pirk CWW, Hepburn HR, Kastberger G, Elzen PJ (2002b) Small hive beetles survive in honeybee prisons by behavioural mimicry. Naturwissenschaften 89:326-328

Ellis JD, Hepburn HR, Delaplane KS, Neumann P, Elzen PJ (2003a) The effects of adult small hive beetles, Aethina tumida (Coleoptera: Nitidulidae), on nests and flight activity of Cape and European honey bees (Apis mellifera). Apidologie 34:399-408
Ellis JD, Hepburn HR, Ellis AM, Elzen PJ (2003b) Social encapsulation of the small hive beetle (Aethina tumida Murray) by European honeybees (Apis mellifera L.). Insectes Soc 50:286-291

Ellis JD, Hepburn HR, Ellis AM, Elzen PJ (2003c) Prison construction and guarding behaviour by European honeybees is dependent on inmate small hive beetle density. Naturwissenschaften 90:382384

Ellis JD, Hepburn HR, Elzen PJ (2004). Confinement of small hive beetles (Aethina tumida) by Cape honeybees (Apis mellifera capensis). Apidologie 35:389-396

Elzen PJ, Baxter JR, Westervelt D, Randall C, Delaplane KS, Cutts L., Wilson WT (1999) Field control and biology studies of a new pest species, Aethina tumida Murray (Coleoptera, Nitidulidae) attacking European honey bees in the Western hemisphere. Apidologie 30:361-366

Hepburn HR, Radloff SE (1998) Honeybees of Africa. Springer, Heidelberg

Hood MW (2004) The small hive beetle, Aethina tumida: a review. Bee World 85:51-59

Imdorf A, Buehlmann G, Gerig L, Kilchenmann V, Wille H (1987) Überprüfung der Schätzmethode zur Ermittlung der Brutfläche und der Anzahl Arbeiterinnen in freifliegenden Bienenvölkern. Apidologie 18:137-146

Lundie AE (1940) The small hive beetle Aethina tumida. Science Bulletin 220, Department of Agr Forestry, Government Printer, Pretoria, South Africa

Mutsaers M (1991) Bees in their natural environment in south-western Nigeria. Niger Field 56:3-18

Mutsaers M (2006) Beekeepers' observations on the small hive beetle (Aethina tumida) and other pests in bee colonies in West and East Africa. In: Veselý V, Titěra D (eds) Proceedings of the 2nd European conference of Apidology, Prague, Czech Republic, p 44

Neumann P, Elzen PJ (2004) The biology of the small hive beetle (Aethina tumida, Coleoptera: Nitidulidae): gaps in our knowledge of an invasive species. Apidologie 35:229-247

Neumann P, Härtel S (2004) Removal of small hive beetle (Aethina tumida) eggs and larvae by African honeybee colonies (Apis mellifera scutellata). Apidologie 35:31-36

Neumann P, Pirk CWW, Hepburn HR, Solbrig AJ, Ratnieks FLW, Elzen PJ, Baxter JR (2001) Social encapsulation of beetle parasites by Cape honeybee colonies (Apis mellifera capensis Esch.). Naturwissenschaften 88:214-216

Pettis JS (2003) A scientific note on Varroa destructor resistance to Coumaphos in the United States. Apidologie 35:91-92

Schmolke MD (1974) A study of Aethina tumida: the small hive beetle. Project Report, University of Rhodesia, p 178

Spiewok S, Neumann P (2006) Cryptic low-level reproduction of small hive beetles in honeybee colonies. J Apic Res 45:47-48

Spreafico M, Eördegh FR, Bernardinelli I, Colombo M (2001) First detection of strains of Varroa destructor resistant to Coumaphos. Results of laboratory tests and field trials. Apidologie 32:49-55 